\title{
Simulating Nutrient Uptake Dynamics in Plankton Models: A Case Study for the Cilician Basin Marine Ecosystem
}

\author{
Ekin Akoglu ${ }^{1, *}(\mathbb{C}$ \\ ${ }^{1}$ Middle East Technical University, Institute of Marine Sciences, P.O. Box 28, 33731, Erdemli, Mersin, Turkey.
}

\section{Article History}

Received 02 August 2019

Accepted 03 April 2020

First Online 07 April 2020

\section{Corresponding Author}

Tel.: +903245213434

E-mail: ekin@ims.metu.edu.tr

\section{Keywords}

Ecological modelling

Biogeochemistry

Cilician basin

Primary production

Nutrient uptake kinetics

\begin{abstract}
The primary productivity in the Cilician Basin is severely constrained by phosphorus limitation due to high $\mathrm{N}: \mathrm{P}$ ratios in the external nutrient inputs. Therefore, special attention is required when the dynamics of plankton is modelled. Acknowledging that mathematical formulation of nutrient uptake by phytoplankton in ecosystem models is crucial as it determines the degree of realism of the representation of biogeochemical dynamics, a plankton model was developed by utilising two widely adopted approaches; i) Monod nutrient uptake kinetics, and ii) Droop nutrient uptake kinetics, to delineate the seasonality of phytoplankton in an attempt to establish a mechanistic biogeochemical model of the Cilician Basin. The model was validated against field data from Erdemli Time Series stations in the region and differences between the approaches were compared. The model successfully simulated the phosphorus limitation in the basin; however, the scenario with Droop kinetics had a better fit to the field data. Both scenarios reproduced the primary productivity in the region. Overall, the results indicated that implementation of Monod kinetics generally sufficed to represent the seasonality of phytoplankton, whereas in environments with severe temporal nutrient scarcity, i.e. the Cilician Basin, implementation of Droop kinetics is required to represent the phytoplankton dynamics more realistically.
\end{abstract}

\section{Introduction}

The Eastern Mediterranean Sea, in particular the Cilician Basin where Erdemli Time Series (ETS) stations are located, is characterised by oligotrophic offshore waters and nutrient-rich coastal waters along the coasts of Antakya, Adana and Mersin due to high nutrient inputs from rivers (Krom, Herut, \& Mantoura, 2004; Doğan-Sağlamtimur \& Tuğrul, 2004.). It has very high nitrogen to phosphorus (N:P) ratio (>> 16:1) and, considering the Redfield ratio, can be classified as phosphorus-limited in terms of primary productivity. The dominant phytoplankton groups in the Cilician Basin are diatoms and dinoflagellates in the coastal zone and cyanobacteria in the offshore waters (Yılmaz, 2006). The dynamics of phytoplankton is characterised by biannual blooms; one in late winter/early spring and the other in the autumn season (Krom, Groom, \& Zohary, 2003). However, this does not necessitate that primary productivity halts at times of severe nutrient limitation considering that primary producers also rely on their intracellular nutrient concentrations, i.e. quotas, for growth (Droop, 1973). Therefore, both external and internal (intracellular) nutrient concentrations influence the nutrient uptake dynamics, hence growth, of phytoplankton.

Nutrient uptake dynamics by primary producers in marine ecosystems has long been investigated (Paasche, 
1973; Harrison, Parslow, \& Conway, 1989; Moloney \& Field, 1989). Two widely adopted mathematical formulations have emerged in the literature: i) Monod nutrient uptake kinetics (Monod, 1942), and ii) luxurious (also known as Droop) nutrient uptake kinetics (Droop, 1973). The former approach assumes that nutrient uptake by phytoplankton is a function of external nutrient concentrations only, whereas the latter approach considers that there is an intracellular balance of nutrients in phytoplankton and the external nutrient uptake dynamics is coupled to these intracellular nutrient ratios. Both approaches have been widely acclaimed in mechanistic models; however, Droop nutrient uptake kinetics has increasingly been used in sophisticated aquatic biogeochemical models (e.g. WASP: Martin, Ambrose, \& Wool, 2017; BFM: Vichi et al., 2013; ERSEM: Butenschön et al., 2016).

Hand in hand with mechanistic modelling, time series measurements in marine environments are crucial for the validation and fine-tuning of these models. These measurements also enable the discovery of long-term changes and trends in confined marine geographical locations. Not only do these measurements reveal the contrasting oceanographic properties of the sampling site over time, e.g. at times of episodic/continuous events such as pollution and atmospheric deposition, but also they provide an invaluable tool to discover the impact of global phenomenon such as climate change on marine systems. Considering all these aspects, Erdemli Time Series (ETS) long-term monitoring project is an invaluable ongoing effort. Hence, combining such multiannual time series data with mechanistic modelling is a versatile tool for investigating ecosystem dynamics. Therefore, in this study, the aim is two-fold. First, a simplistic single phytoplankton functional type (PFT) model was developed, and a comparison of two widely adopted nutrient uptake kinetics that have been employed in sophisticated plankton models was carried out to determine the best approach for modelling the peculiarities of the primary productivity in the region. Second, ETS data was incorporated into the model in terms of both formulation and skill assessment to take the first step to establish a sophisticated biogeochemical model of the region that could be used to scrutinise the biogeochemical dynamics of the coastal ecosystem in the Turkish part of the Eastern Mediterranean Sea.

\section{Materials and Methods}

\section{The Geographical Domain of Samples}

ETS stations are located in the eastern part of the Cilician Basin shelf in front of Limonlu, Erdemli vicinity in the Eastern Mediterranean Sea (Figure 1). The sampling dates back to the beginning of 2013 and has been carried out monthly ever since.

\section{The Model}

A simple N2PD2 (two Nutrients, one Phytoplankton and two Detritus) model was developed to investigate the changes caused by the implementation of Monod and Droop nutrient uptake kinetics on phytoplankton dynamics in the region. The model has eight state variables; dissolved inorganic nitrogen (DIN) and dissolved inorganic phosphorus (DIP) as nutrient resources, particulate organic nitrogen (PON) and particulate organic phosphorus (POP) as detrital compartments, a phytoplankton group represented in carbon biomass, and two quota variables in order to track the internal $\mathrm{N}$ and $\mathrm{P}$ quotas of phytoplankton in line with the Droop nutrient uptake kinetics if employed. The flow diagram of the model is shown in Figure 2 . The

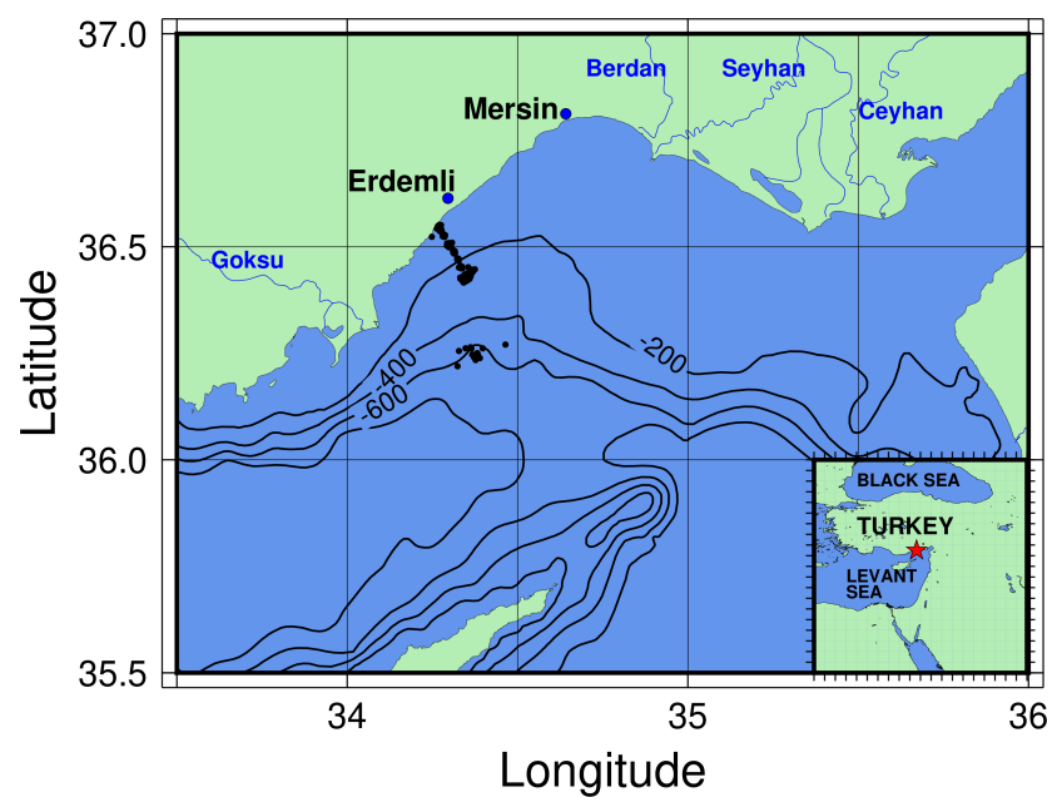

Figure 1. The locations of the Erdemli time series stations (black dots) in the Mersin Bay and the geographical position of the sampling site (red star) shown on the small map (bottom right). 
model includes only one PFT compartment because ETS measurements did not discriminate among different phytoplankton taxa but only included bulk Chl-a measurements. This hindered implementation of detailed representation and validation of different phytoplankton groups in the model.

The model has two alternative formulations; i) Droop nutrient uptake kinetics (Table 1) and ii) Monod nutrient uptake kinetics (Table 2). For the Droop nutrient uptake kinetics, a phi coefficient was utilised for phytoplankton growth and defined as a function of internal nutrient quotas of nitrogen and phosphorus (Droop, 1973). Further, the uptake of external nutrients was scaled by a function of these dynamic internal nutrient quotas as in Rhee (1973). For the Monod nutrient uptake kinetics (Monod, 1942), fixed internal nutrient quotas were used as per the Redfield ratio, and the growth was constrained by the Liebig's law of the minimum depending on the ambient nutrient concentrations. The temperature effect on the growth of the phytoplankton group was formulated with a $Q_{10}$ temperature limitation function. Temperature measurements at 10 meters depth from all stations were used to force the phytoplankton growth function to simulate the impact of temperature on primary productivity. Zooplankton grazing on phytoplankton was represented via a quadratic closure term, i.e. phytoplankton mortality, that is formulated to include non-predation and predation mortality fluxes combined implicitly as sometimes practised in plankton models (Crise, Crispi, \& Mauri, 1998).

A similar approach to Cossarini and Solidoro (2008) was employed to simulate the impact of nutrient entrainment to the euphotic zone during spring and fall. However, contrary to injecting nutrients from the reserve of nutrients in the deeper layers of the model domain at specific dates as in Cossarini and Solidoro (2008), the remineralisation rates were increased an order of magnitude for a specific period during early spring and late summer, i.e. starting from March until April and from July until August. The parameters used in the model are given in Table 3.

The impact of different nutrient uptake kinetics on phytoplankton dynamics were compared with two scenarios; i) Monod scenario where nutrient uptake kinetics only relied on extracellular nutrient concentrations (Table 1), and ii) Droop scenario where luxurious nutrient uptake kinetics was employed (Table 2). The scenarios were run for four years, being the first three years as spin-up period. The results from the final year of the simulations were compared.

\section{Model Validation}

The monthly-averaged $\mathrm{Chl}-a, \mathrm{NO}_{3}-\mathrm{NO}_{2}$ and $\mathrm{PO}_{4}$ measurements at 10 meters depth from ETS project stations were used to validate the model scenarios and assess their skills. The skill assessments of the model scenarios were carried out via commonly used model skill metrics: the sum of squared deviations of the model predictions from observations, the root mean square distance, the correlation coefficient between model predictions and observations, reliability index values and percentage model bias.

The sum of squared deviations (SS) of model predictions from observations was calculated as:

$$
S S=\sum_{i=0}^{n}\left(P_{i}-O_{i}\right)^{2}
$$

where $P_{i}$ is the ith prediction of a total of $n$ predictions and $O_{i}$ is the $i$ th observation of a total of $n$ observations.

The root mean square distance (RMSD), which is a measure of goodness of fit between data and predictions, was calculated as:

$$
R M S D=\sqrt{\frac{\sum_{i=1}^{n}\left(P_{i}-O_{i}\right)^{2}}{n}}
$$

The Pearson correlation coefficient ( $r$ ) was calculated as:

$$
r=\frac{\sum_{i=1}^{n}\left(O_{i}-\bar{O}\right) \times\left(P_{i}-\bar{P}\right)}{\sqrt{\sum_{i=1}^{n}\left(O_{i}-\bar{O}\right)^{2} \times \sum_{i=1}^{n}\left(P_{i}-\bar{P}\right)^{2}}}
$$

where $\bar{O}$ and $\bar{P}$ are observation and prediction averages, respectively. The correlation coefficient between two data sets shows the degree that both sets increase or decrease in agreement with one another.

The reliability index indicates the factor by which the model predictions differ from the observations. It is expected to be close to unity for a model with high predictive capacity. The reliability index (RI) was calculated as:

$$
R I=\exp \left(\sqrt{\frac{1}{n} \times \sum_{i=1}^{n}\left(\log \frac{O_{i}}{P_{i}}\right)^{2}}\right)
$$

Finally, the percentage model bias, which is the sum of the model errors normalised by the observations, was calculated as:

$$
\text { Pbias }=\frac{\sum_{i=1}^{n}\left(P_{i}-O_{i}\right)}{\sum_{i=1}^{n} O_{i}} \times 100
$$

A positive bias means that the model overestimates the observations, and a negative bias means vice versa. 


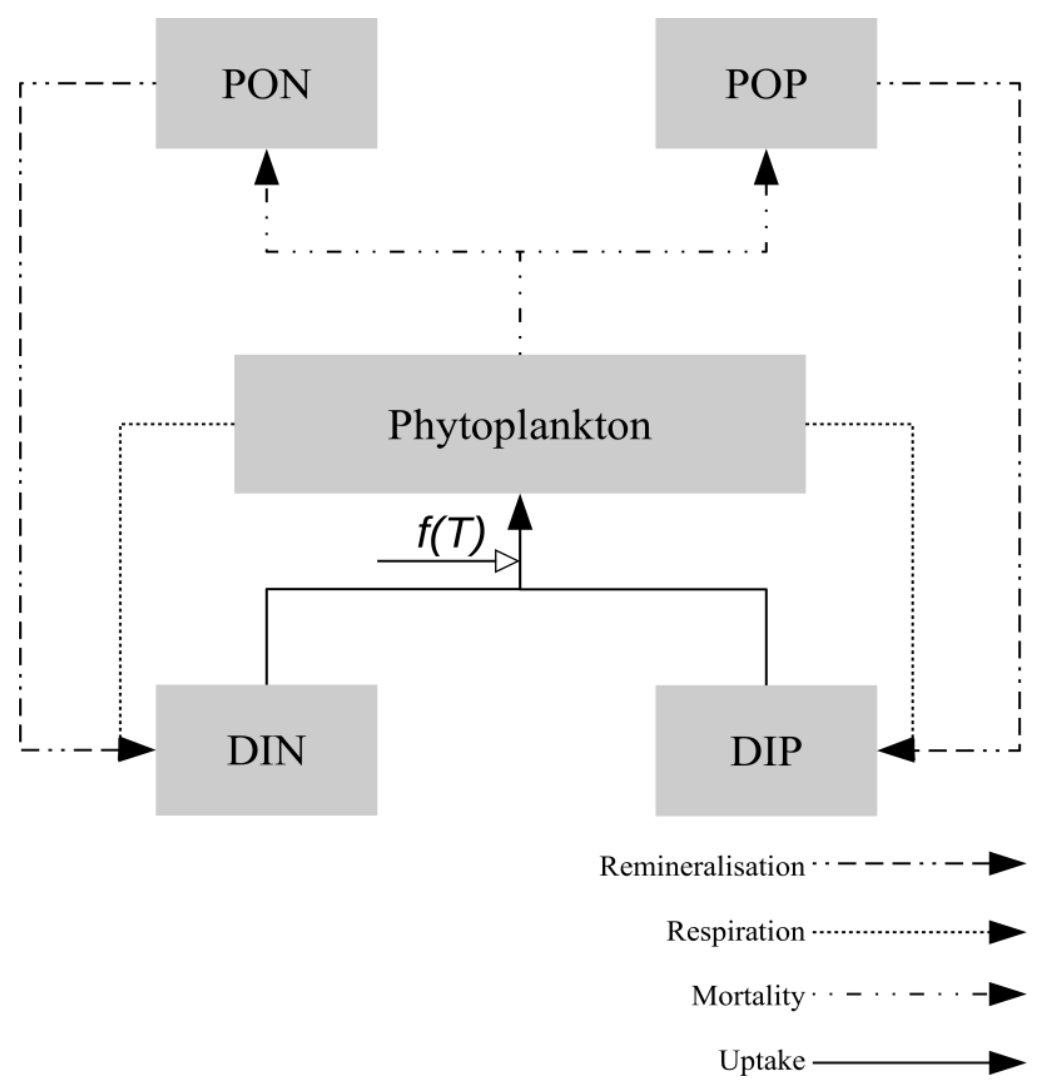

Figure 2. The model compartments and their respective flows. DIN and DIP denote dissolved inorganic nitrogen and phosphorus, respectively. PON and POP denote particulate organic nitrogen and phosphorus, respectively. $f(T)$ denotes the temperature effect on phytoplankton growth.

Table 1. Model formulation with Droop nutrient uptake kinetics. $\mathrm{N}$ denotes nitrogen, $\mathrm{P}$ denotes phosphorus, DIN and DIP denote dissolved inorganic nitrogen and phosphorus, respectively, PON and POP denote particulate organic nitrogen and phosphorus,

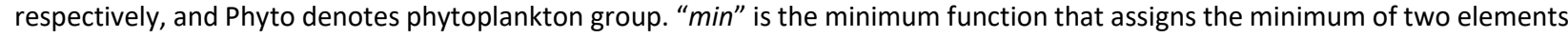
compared. $f(T)$ is the function for temperature limitation on phytoplankton growth. For the explanation of the terms in the equations, see Table 3

$$
\begin{aligned}
& \frac{d\left[N_{\text {Quota }}\right]}{d t}=f(T) * u_{\max } * \frac{D I N}{k_{\text {DIN }}+D I N} * \frac{k_{q N}}{k_{q N}+\left(\frac{N_{\text {Quota }}}{\text { Phyto }}-q_{0 N}\right)} * \text { Phyto }-l_{P R} * N_{\text {Quota }}-l_{P M} * \text { Phyto }^{2} * r n c_{-} t \\
& \frac{d\left[P_{\text {Quota }}\right]}{d t}=f(T) * u_{\text {max }} * \frac{D I P}{k_{D I P}+D I P} * \frac{k_{q P}}{k_{q N}+\left(\frac{P_{\text {Quota }}}{\text { Phyto }}-q_{0 P}\right)} * \text { Phyto }-l_{P R} * P_{\text {Quota }}-l_{P M} * \text { Phyto }{ }^{2} * r p c_{-} t \\
& \frac{d[D I N]}{d t}=-f(T) * u_{\max } * \frac{D I N}{k_{D I N}+D I N} * \frac{k_{q N}}{k_{q N}+\left(\frac{N_{\text {Quota }}}{\text { Phyto }}-q_{\text {ON }}\right)} * \text { Phyto }+l_{D N} * P O N+l_{P R} * N_{\text {Quota }} \\
& \frac{d[D I P]}{d t}=-f(T) * u_{\max } * \frac{D I P}{k_{D I P}+D I P} * \frac{k_{q P}}{k_{q N}+\left(\frac{P_{\text {Quota }}}{\text { Phyto }}-q_{0 P}\right)} * \text { Phyto }+l_{D P} * P O P+l_{P R} * P_{Q u o t a} \\
& \frac{d[\text { Phyto }]}{d t}=f(T) * u_{\text {max }} * \text { phi } * \text { Phyto }-l_{P R} * \text { Phyto }-l_{P M} * \text { Phyto }^{2} \\
& \frac{d[P O N]}{d t}=l_{P M} * P_{h y t o}{ }^{2} * r n c_{-} t-l_{D N} * P O N \\
& \frac{d[P O P]}{d t}=l_{P M} * P h y t o^{2} * r p c_{-} t-l_{D P} * P O P \\
& p h i=\min \left(\left(1-\frac{q_{0 N}}{\frac{N_{Q u o t a}}{\text { Phyto }}}\right),\left(1-\frac{q_{0 P}}{\frac{P_{\text {Quota }}}{\text { Phyto }}}\right)\right) \\
& f(T)=Q_{10}^{(T-20) /} \\
& \text { rnc_t }=N_{\text {Quota }} / \text { Phyto } \\
& r p c_{-} t=P_{\text {Quota }} / \text { Phyto }
\end{aligned}
$$


Table 2. Model formulation with Monod nutrient uptake kinetics. N denotes nitrogen, $\mathrm{P}$ denotes phosphorus, DIN and DIP denote dissolved inorganic nitrogen and phosphorus, respectively, PON and POP denote particulate organic nitrogen and phosphorus, respectively, and Phyto denotes phytoplankton group. " $\min ^{\prime}$ is the minimum function that assigns the minimum of two elements compared. $f(T)$ is the function for temperature limitation on phytoplankton growth. For the explanation of the terms in the equations, see Table 3

$$
\begin{gathered}
\frac{d[D I N]}{d t}=-f(T) * u_{\max } * \min \left(\frac{D I N}{k_{D I N}+D I N}, \frac{D I P}{k_{D I P}+D I P}\right) * \text { Phyto } * r n c+l_{D N} * P O N+l_{P R} * \text { Phyto } * r n c \\
\frac{d[D I P]}{d t}=-f(T) * u_{\max } * \min \left(\frac{D I N}{k_{D I N}+D I N}, \frac{D I P}{k_{D I P}+D I P}\right) * P h y t o * r n p+l_{D P} * P O P+l_{P R} * P h y t o * r p c \\
\frac{d[P h y t o]}{d t}=f(T) * u_{\max } * \min \left(\frac{D I N}{k_{D I N}+D I N}, \frac{D I P}{k_{D I P}+D I P}\right) * P h y t o *-l_{P R} * P h y t-l_{P M} * P h y t o^{2} \\
\frac{d[P O N]}{d t}=l_{P M} * P_{y y t o}^{2} * r n c-l_{D N} * P O N \\
\frac{d[P O P]}{d t}=l_{P M} * \text { Phyto }^{2} * r p c-l_{D P} * P O P \\
f(T)=Q_{10}^{(T-20) / 10}
\end{gathered}
$$

\begin{tabular}{|c|c|c|c|}
\hline Parameter/Units & $\begin{array}{l}\text { Literature } \\
\text { Value }\end{array}$ & $\begin{array}{l}\text { Fitted } \\
\text { Value }\end{array}$ & Explanation \\
\hline \multicolumn{4}{|c|}{ Quota parameters } \\
\hline $\mathrm{q}_{\mathrm{ON}}(\mathrm{mol} \mathrm{N}: \mathrm{mol} \mathrm{C})$ & 0.014-0.061 & 0.061 & Minimum cell quota of nitrogen for growth (Sommer, 1991) \\
\hline $\mathrm{q}_{\mathrm{OP}}(\mathrm{mol} \mathrm{P}: \mathrm{mol} \mathrm{C})$ & $\begin{array}{l}0.002- \\
0.011\end{array}$ & 0.011 & Minimum cell quota of phosphorus for growth (Cossarini \& Solidoro, 2008) \\
\hline $\mathrm{k}_{\mathrm{qN}}(\mathrm{mol} \mathrm{N}: \mathrm{mol} \mathrm{C})$ & - & 0.8 & Half-saturation constant for intracellular nitrogen uptake \\
\hline $\mathrm{k}_{\mathrm{qP}}(\mathrm{mol} \mathrm{P}: \mathrm{mol} \mathrm{C})$ & $0.0775^{*}$ & 0.085 & $\begin{array}{l}\text { Half-saturation constant for intracellular phosphorus uptake (Lessin, Lips \& } \\
\text { Raudsepp, 2007) }\end{array}$ \\
\hline \multicolumn{4}{|c|}{ Phytoplankton parameters } \\
\hline$u_{\max }\left(d^{-1}\right)$ & 0.87 & 0.6 & Maximum specific growth rate (Sunda, Shertzer, \& Hardison, 2009) \\
\hline $\mathrm{k}_{\mathrm{N}}\left(\mu \mathrm{M} \mathrm{N} \mathrm{L}^{-1}\right)$ & 0.8 & 0.8 & Half-saturation constant for DIN (Llebot, Spitz, Solé, \& Estrada, 2010) \\
\hline $\mathrm{k}_{\mathrm{P}}\left(\mu \mathrm{M} \mathrm{P} \mathrm{L}^{-1}\right)$ & 0.085 & 0.085 & Half-saturation constant for DIP (Llebot et al., 2010) \\
\hline$I_{P R}\left(d^{-1}\right)$ & 0.01 & 0.01 & Respiration (Fennel \& Neumann, 2004) \\
\hline$I_{P M}\left(d^{-1}\right)$ & 0.06 & 0.06 & Mortality (Oguz, Ducklow, Purcell, \& Malanotte-Rizzoli, 2001) \\
\hline $\mathrm{Q}_{10}$ & 1.2 & 1.2 & $Q_{10}$ coefficient for temperature effect on growth (Oguz et al., 2001) \\
\hline rnc & - & 0.1509 & Nitrogen to carbon ratio of phytoplankton in Monod scenario (Redfield ratio) \\
\hline rpc & - & 0.0094 & Phosphorus to carbon ratio of phytoplankton in Monod scenario (Redfield ratio) \\
\hline \multicolumn{4}{|r|}{ 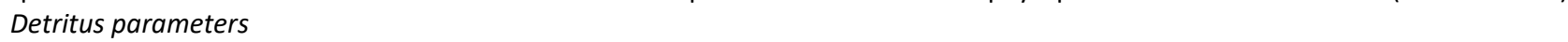 } \\
\hline $\operatorname{lDN}_{\mathrm{DN}}\left(\mathrm{d}^{-1}\right)$ & 0.001 & 0.001 & Remineralisation to DIN (Fennel \& Neumann, 2004) \\
\hline$I_{D P}\left(d^{-1}\right)$ & 0.0005 & 0.001 & Remineralisation to DIP (Cossarini \& Solidoro, 2008) \\
\hline
\end{tabular}

Table 3. Model parameters

* Converted value from g P:g C to mol P:mol C

\section{Results}

\section{Model Skill}

The validation and skill assessment of the two model scenarios were done against ETS data. The simulated phytoplankton biomass by the model was compared to $\mathrm{Chl}-\mathrm{a}$ derived phytoplankton biomass from the ETS measurements using a carbon-to-chlorophyll (C:Chl) ratio of 50 (De Jonge, 1980 and references therein). Both scenarios reproduced the seasonality of the phytoplankton bloom, i.e. biannual blooms, in the area; however, simulated spring bloom biomass was higher than observations. Further, during summer and winter seasons, both scenarios overestimated biomass of phytoplankton. For phytoplankton biomass, the SS value was lower for Droop scenario than Monod scenario (Figure 3).
Further, simulated DIN, DIP, and phytoplankton concentrations were compared to ETS sampled values using Taylor diagrams by comparing calculated model skill metrics (Figure 4). The calculated biases in all state variables were much lower in Droop scenario. The biases of phytoplankton, DIN and DIP were 14.33, 374.95 and 40.59 in Monod scenario and 0.60, -49.05, 27.65 in Droop scenario, respectively. The correlation coefficient of DIN (0.64) in Droop scenario was much higher than the correlation coefficient of DIN (0.34) in Monod scenario. The correlation coefficients were comparable for DIP in both scenarios ( 0.30 in Monod and 0.28 in Droop scenarios). In Droop and Monod scenarios, the correlation coefficients for phytoplankton were in favour of Droop scenario (0.76 in Monod scenario and 0.81 in Droop scenario). RMS distances were less for phytoplankton and DIN in Droop scenario compared to Monod scenario. The RMS distances were similar in both 

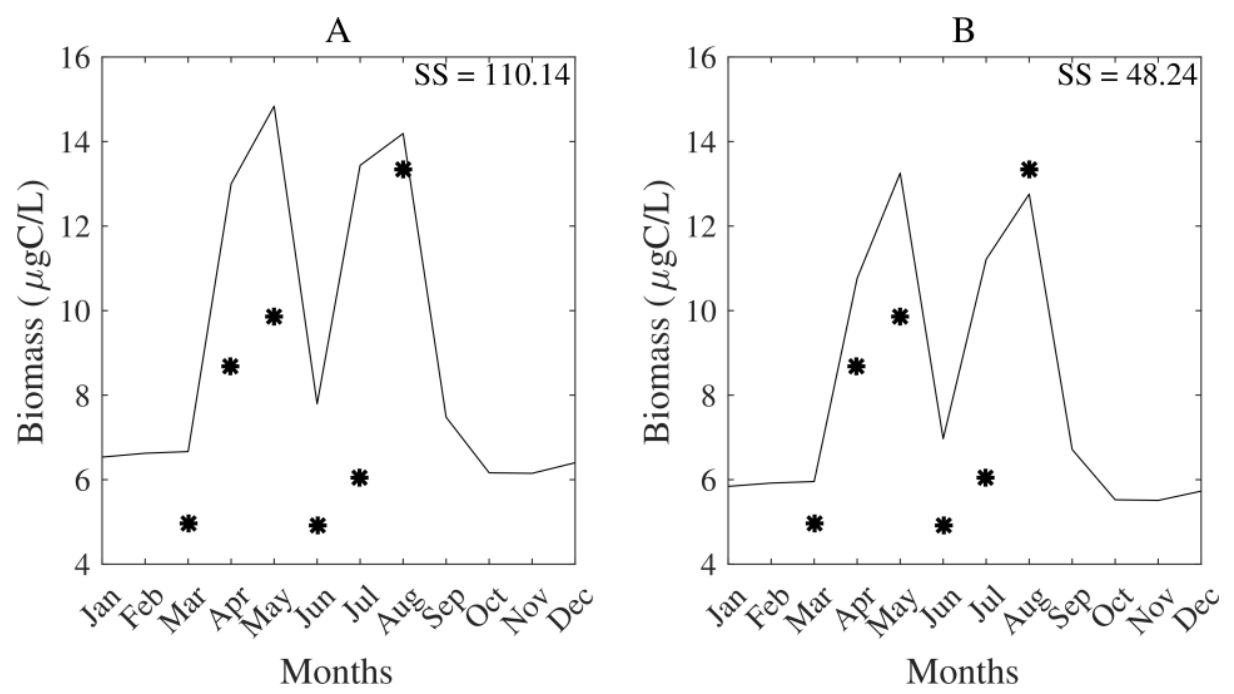

Figure 3. Model-data comparison of phytoplankton biomass as simulated by the model in (A) Monod scenario and (B) Droop scenario (black lines) against Chl- $a$ derived phytoplankton biomass (stars) from ETS data.
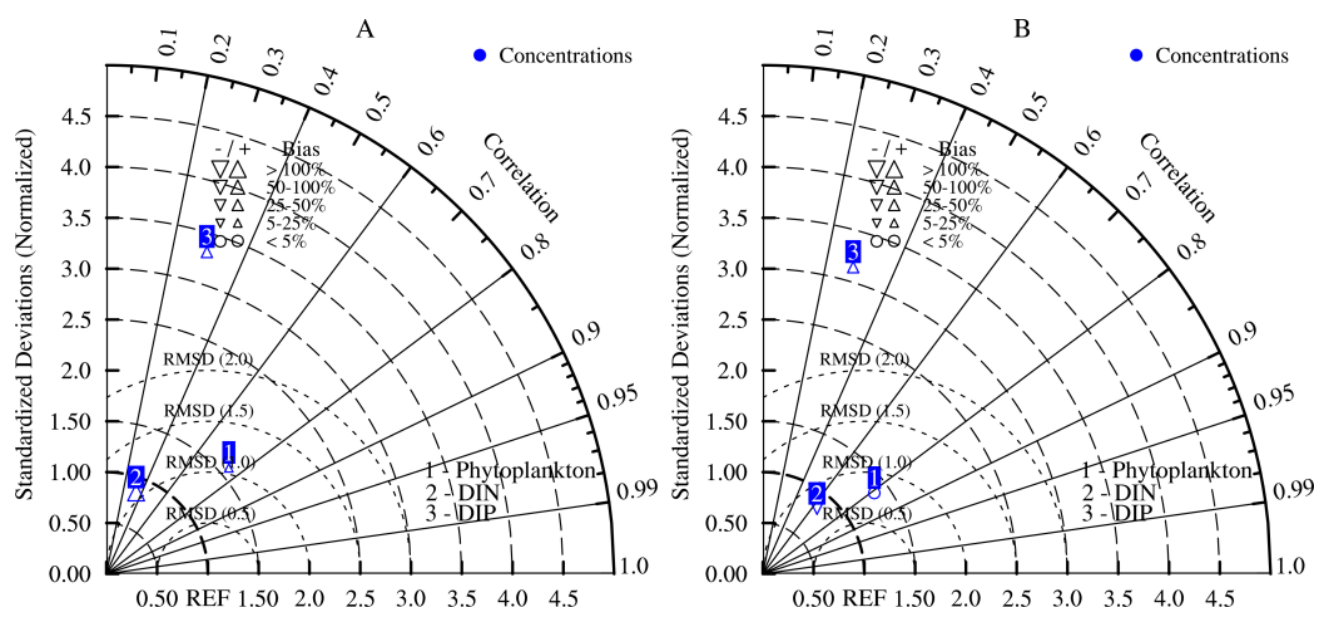

Figure 4. Taylor diagram showing the model-data comparison of phytoplankton, DIN and DIP as simulated by the model in (A) Monod scenario and (B) Droop scenario against ETS data.

scenarios for DIP. The reliability indices were closer to unity in Droop scenario compared to Monod scenario for phytoplankton (1.22 in Monod scenario and 1.16 in Droop scenario). Considering DIN, the reliability indices were 2.02 in Monod scenario and 1.41 in Droop scenario. The reliability indices were similar for DIP in both scenarios; however, slightly in favour of Droop scenario (1.31 in Monod scenario and 1.28 in Droop scenario).

\section{Comparison of Monod and Droop Nutrient Uptake Kinetics}

Using Monod and Droop nutrient uptake kinetics with the parameterisations in Table 3 , the modelled region was simulated to be phosphorus limited (Figure 5 and 6). The average N:P ratio was 22.20 in Droop scenario and 202.92 in Monod scenario.

The spring and fall phytoplankton blooms were more pronounced in Monod scenario than Droop scenario. The maximum peak biomasses were $20.38 \mu \mathrm{g}$ $\mathrm{C} \mathrm{L}^{-1}$ and $20.49 \mu \mathrm{g} \mathrm{C} \mathrm{L}{ }^{-1}$ in spring and fall respectively in Monod scenario. In contrast, the maximum peak biomasses were $17.64 \mu \mathrm{g} \mathrm{CL}^{-1}$ both in spring and fall in Droop scenario. The peak biomasses simulated by the two scenarios both overestimated the in-situ Chl-a derived spring biomasses and almost matched the peak biomasses in fall. Further, in summer (from June to August) the average biomass of phytoplankton was $11.21 \mu \mathrm{g} \mathrm{C} \mathrm{L}^{-1}$ in Droop scenario, whereas it was 13.44 $\mu \mathrm{g} \mathrm{CL^{-1 }}$ in Monod scenario. Similarly, the annual average biomass of phytoplankton was higher in Monod scenario (9.11 $\left.\mu \mathrm{g} \mathrm{C} \mathrm{L}^{-1}\right)$ and lower in Droop scenario (8.01 $\mu \mathrm{g} \mathrm{C} \mathrm{L}^{-}$ $\left.{ }^{1}\right)$. Average total primary productivity was calculated as $192.61 \mathrm{mg} \mathrm{C} \mathrm{m}^{-2} \mathrm{~d}^{-1}\left(72.13 \mathrm{~g} \mathrm{C} \mathrm{m}^{-2} \mathrm{y}^{-1}\right)$ in Droop scenario and $182.68 \mathrm{mg} \mathrm{C} \mathrm{m}^{-2} \mathrm{~d}^{-1}\left(66.68 \mathrm{~g} \mathrm{C} \mathrm{m}^{-2} \mathrm{y}^{-1}\right)$ in Monod scenario. 

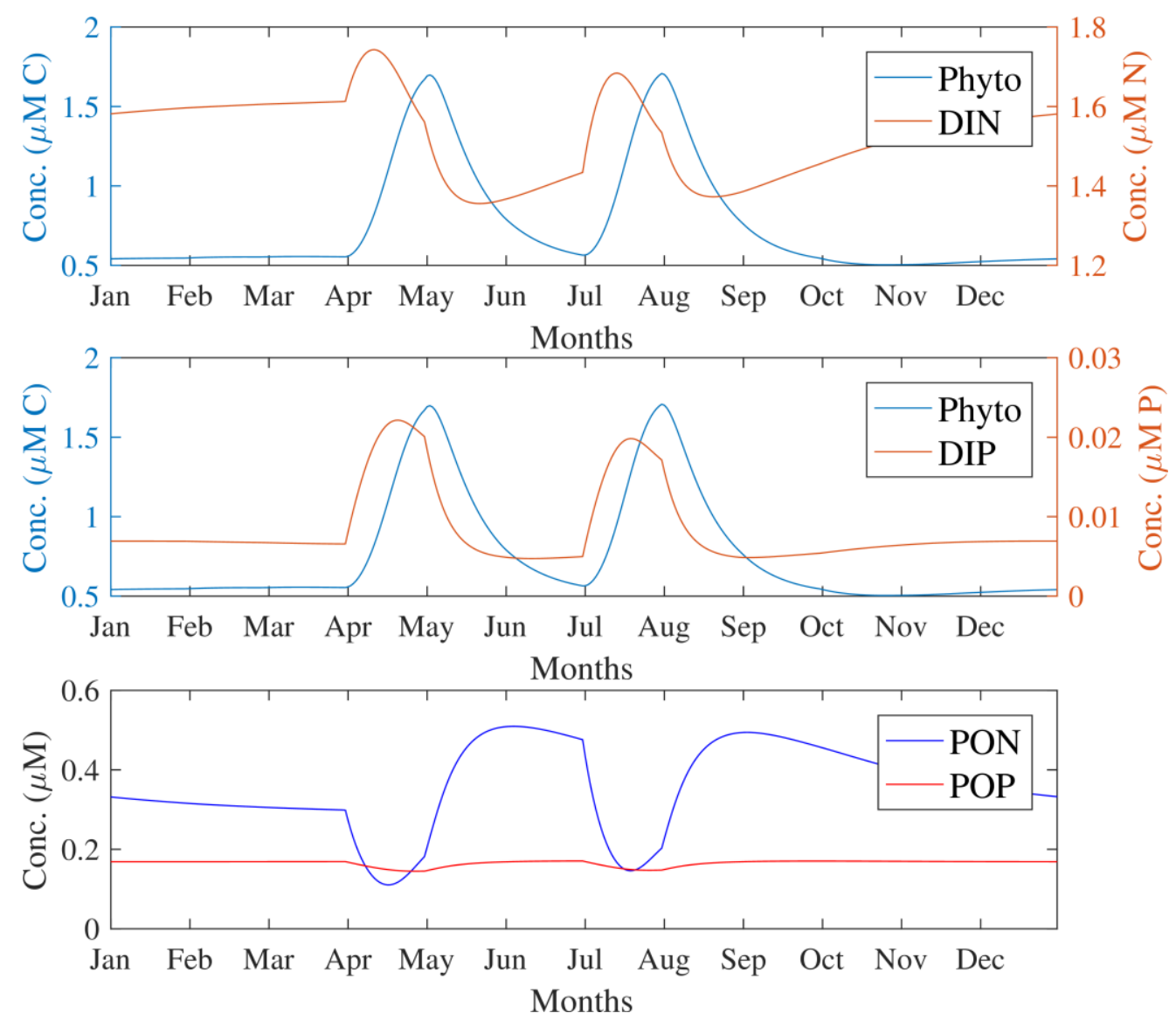

Figure 5. Simulation results of Monod scenario. The concentrations are in $\mu \mathrm{M}$ ( $\mu \mathrm{mol} / \mathrm{L}$ ).
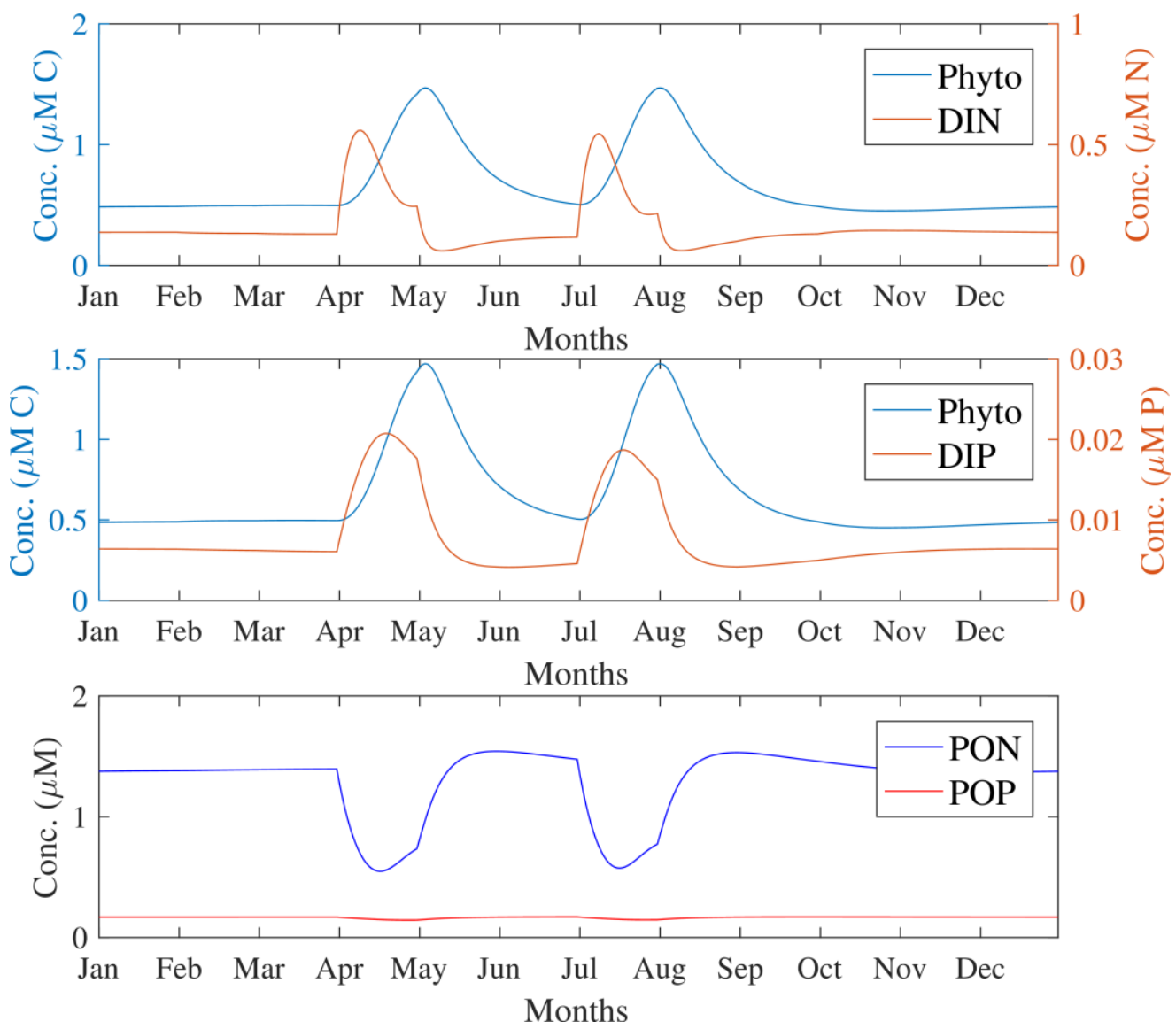

Figure 6. Simulation results of Droop scenario. The concentrations are in $\mu \mathrm{M}(\mu \mathrm{mol} / \mathrm{L})$. 


\section{Discussion}

Monod nutrient uptake kinetics caused much higher phytoplankton peaks during blooms. However, the model overestimated the observed peak biomasses in spring and closely matched the peak biomasses in fall both in Monod and Droop scenarios. The overestimation in spring season was due to the formulation employed in the model following Cossarini and Solidoro (2008) to simulate the nutrient enrichment in the water column with the onset of spring and fall. This formulation assumed a much stronger nutrient availability in the euphotic zone in spring compared to fall; hence, the biomass values simulated in both scenarios in spring were overestimated. Further, the background biomass levels in summer were higher in Monod scenario. This high background levels showed that simulating a higher standing stock of phytoplankton was possible with Monod nutrient uptake kinetics compared to the model with Droop nutrient uptake kinetics. However, the skill assessment of the models with Monod and Droop nutrient uptake kinetics was in favour of the Droop-type model (Figure 3 and 4). When Droop nutrient uptake kinetics was applied, the statistical values indicating model skill, i.e. the sum of squared deviations of predictions from observations, the root mean square distance, correlation coefficient, reliability index, and model bias, were generally improved compared to the model with Monod nutrient uptake kinetics. This improvement could partly be attributed to the lower background biomasses simulated in Droop scenario.

The simulated primary production values were comparable to many literature estimates that varied between $\sim 20$ to $\sim 150 \mathrm{~g} \mathrm{C} \mathrm{m}^{-2} \mathrm{y}^{-1}$ for the Eastern Mediterranean Sea (Siokou-Frangou et al., 2010 and references therein). Specifically, for Mersin Bay, Yucel (2013) estimated primary production between 65.4$151.2 \mathrm{~g} \mathrm{C} \mathrm{m}^{-2} \mathrm{y}^{-1}$. Considering that many studies reported the average primary productivity in the Eastern Mediterranean Sea around $60-80 \mathrm{~g} \mathrm{C} \mathrm{m}^{-2} \mathrm{y}^{-1}$ (Krom, Groom, \& Zohary, 2003), the model successfully reproduced the primary production in the region both in Monod and Droop scenarios.

The $\mathrm{N}: \mathrm{P}$ ratio in Droop scenario was close to the values in the Eastern Mediterranean Sea. Krom, Kress, Brenner, and Gordon (1991) reported the N:P ratio in the deep waters of the Eastern Mediterranean as $\approx 28$ and Krom, Emeis, and Van Cappellen (2010) stated that strong phosphorus limitation in the Eastern Mediterranean Sea is due to high N:P ratio in all external nutrient inputs to the region. This value can be expected to be higher for coastal waters such as the model domain, i.e. the Cilician Basin, with high riverine inputs and high exposure to atmospheric deposition of nutrients whose N:P ratios could be as high as 233 (Kocak, Kubilay, Tugrul, \& Mihalopoulos, 2010). This may contribute to increased $\mathrm{N}: \mathrm{P}$ discrepancy in the coastal waters. Therefore, the high N:P ratio simulated in Monod scenario could be considered as debatable. This situation was highlighted in the high bias value calculated for DIN in Monod scenario (Figure 4). The fundamental mechanism behind the observation of such high $\mathrm{N}: \mathrm{P}$ ratio in Monod scenario could be the decoupling of nutrient uptake by phytoplankton from their intracellular nutrient ratios in Monod nutrient uptake kinetics; hence, assuring an exaggerated nutrient uptake rate depending on the external nutrient concentrations solely constrained by the respective halfsaturation constants of the phytoplankton group. This decoupling caused higher growth of phytoplankton when there was plentiful nutrient and lower growth when severe nutrient scarcity occurred, which lead to inadequate representation of in-situ observations in Monod scenario compared to Droop scenario although the half-saturation constants of phytoplankton for DIN and DIP remained unchanged. Sommer (1991) states that Droop nutrient uptake kinetics could better describe the nutrient-limited growth of phytoplankton dependent on the cellular content of the limiting nutrient compared to the Monod nutrient uptake kinetics, which relies on ambient nutrient concentrations. Further, Cerucci, Jaligama, and Ambrose (2010) confirmed the robustness of the Droop model also for periphyton. In this study, a similar result was obtained for phytoplankton as indicated by the model skill metrics (Figure 4). The model skill metrics of the model with Droop nutrient uptake kinetics outperformed the skill metrics of the model with Monod nutrient uptake kinetics.

The incorporation of one single phytoplankton group in the model could be considered as a limitation of the study. Considering different requirements in terms of nutrient kinetics of different phytoplankton taxa, such a bulk representation of primary producers in one single state variable may hinder the representation of seasonal succession of phytoplankton. However, given the data at hand, the validation of the model could only be possible with one primary producer group because the time series of samples in ETS project included only bulk Chl- $a$ concentration measurements without any differentiation of other pigments that would help the discrimination of different phytoplankton groups. Another consideration of the study is that the data from ETS project stations that were used to drive and validate the model included different depth strata. Although all the stations could be considered as coastal, the combination of stations located shallower than $250 \mathrm{~m}$ with the ones located in the $500 \mathrm{~m}$ isobath (Figure 1) could have degraded the models' skill due to spatial variability. However, this was a necessity because consolidating data from different depth strata was inevitable to obtain monthly time series due to the gaps in the time series of samplings even though the data spanned multiple years. On the other hand, this statistical averaging to obtain the monthly time series for model validation could have dampened the variability that could have been caused by this data consolidation and acted as a mitigating 
factor against degrading the skill of the model.

\section{Conclusion}

The impact of incorporating different nutrient uptake kinetics in a first attempt to establish a mechanistic biogeochemical model of the Cilician Basin by utilising ETS data was investigated. Comparative assessment of model skill metrics showed that, overall, the scenario with the Droop nutrient uptake kinetics was more successful than the scenario with the Monod nutrient uptake kinetics in the representation of the nutrient and phytoplankton dynamics in the region. Further, Droop scenario better represented the observed conditions of the Cilician Basin by ETS samplings as shown by the simulated N:P ratio in its respective scenario. This supported that multi-nutrient, luxurious nutrient uptake kinetics for phytoplankton should be preferred over the conventional Fasham-type modelling (Fasham, Ducklow, \& McKelvie, 1990), in particular, in this severely phosphorus-limited ecosystem of the Cilician Basin, and in general, in the Eastern Mediterranean Sea in order to establish a realistic biogeochemical modelling framework that can represent the biogeochemical conditions of the region.

The model constructed in this study is the first step to establish an operational biogeochemical model for the Cilician Basin and should further be extended with at least two compartments of zooplankton and should be complemented with different PFT compartments. However, the lack of available time series data in the region severely constrains such an effort and its validation. Hence, this effort should be carried out handin-hand with fieldwork to complement one another so that a validated biogeochemical model could be established in the region for operational use.

\section{Acknowledgements}

ETS measurements used in this study were supported by DEKOSIM Project (National Excellence Centre for Marine Ecosystem and Climate Research Deniz Ekosistem ve Iklim Araştırmaları Merkezi, Project Code BAP-08-11-DPT.2012K120880), financed by the Ministry of Development of Turkey.

\section{References}

Butenschön, M., Clark, J., Aldridge, J.N., Allen, J.I., Artioli, Y., Blackford, J., ... Torres, R. (2016). ERSEM 15.06: a generic model for marine biogeochemistry and the ecosystem dynamics of the lower trophic levels. Geoscientific Model Development, 9(4), 1293-1339. https://doi.org/10.5194/gmd-9-1293-2016

Cerucci, M., Jaligama, G. K., \& Ambrose Jr, R. B. (2010). Comparison of the monod and droop methods for dynamic water quality simulations. Journal of Environmental Engineering, 136(10), 1009-1019. https://doi.org/10.1061/(ASCE)EE.1943-7870.0000257

Cossarini, G., \& Solidoro, C. (2008). Global sensitivity analysis of a trophodynamic model of the Gulf of Trieste. Ecological Modelling, 212(1-2), 16-27.

https://doi.org/10.1016/j.ecolmodel.2007.10.009

Crise, A., Crispi, G., \& Mauri, E. (1998). A seasonal threedimensional study of the nitrogen cycle in the Mediterranean Sea: Part I. Model implementation and numerical results. Journal of Marine Systems, 18(1-3), 287-312.

https://doi.org/10.1016/S0924-7963(98)00016-5

De Jonge, V.N. (1980). Fluctuations in the organic carbon to chlorophyll a ratios for estuarine benthic diatom populations. Marine Ecology Progress Series, 2(4), 345353. https://doi.org/10.3354/meps002345

Doğan-Sağlamtimur, N., \& Tuğrul, S. (2004). Effect of riverine nutrients on coastal water ecosystems: a case study from the northeastern Mediterranean shelf. Fresenius Environmental Bulletin, 13, 1288-1294.

Droop, M.R. (1973). Some thoughts on nutrient limitation in algae. Journal of Phycology, 9(3), 264-272. https://doi.org/10.1111/j.1529-8817.1973.tb04092.x

Dugdale, R.C., \& Wilkerson, F.P. (1988). Nutrient sources and primary production in the Eastern Mediterranean. Oceanologica Acta, 9, 179-184.

Fasham, M.J.R., Ducklow, H.W., \& McKelvie, S.M. (1990). A nitrogen-based model of plankton dynamics in the oceanic mixed layer. Journal of Marine Research, 48(3), 591-639. https://doi.org/10.1357/002224090784984678

Fennel, W., \& Neumann, T. (2004). Introduction to the modelling of marine ecosystems, Vol. 72. Amsterdam, The Netherlands, Elsevier, $297 \mathrm{pp}$.

Harrison, P.J., Parslow, J.S., \& Conway, H.L. (1989). Determination of nutrient uptake kinetic parameters: a comparison of methods. Marine Ecology Progress Series, 52, 301-312. https://doi.org/10.3354/meps052301

Koçak, M., Kubilay, N., Tugrul, S., \& Mihalopoulos, N. (2010). Atmospheric nutrient inputs to the northern levantine basin from a long-term observation: sources and comparison with riverine inputs. Biogeosciences, 7(12), 4037. https://doi:10.5194/bg-7-4037-2010

Krom, M.D., Kress, N., Brenner, S., \& Gordon, L.I. (1991). Phosphorus limitation of primary productivity in the eastern Mediterranean Sea. Limnology and Oceanography, 36(3), 424-432.

https://doi.org/10.4319/lo.1991.36.3.0424

Krom, M.D., Groom, S., \& Zohary, T. (2003). The Eastern Mediterranean. In K.D. Black \& G.B. Schimmield (Eds.), Biogeochemistry of marine systems (pp. 91-122). Oxford, UK, Blackwell CRC Press., 372 pp.

Krom, M.D., Herut, B., \& Mantoura, R.F.C. (2004). Nutrient budget for the Eastern Mediterranean: Implications for phosphorus limitation. Limnology and Oceanography, 49(5), 1582-1592.

https://doi.org/10.4319/lo.2004.49.5.1582

Krom, M.D., Emeis, K.C., \& Van Cappellen, P. (2010). Why is the Eastern Mediterranean phosphorus limited? Progress in Oceanography, 85(3-4), 236-244.

https://doi.org/10.1016/j.pocean.2010.03.003

Lessin, G., Lips, I., \& Raudsepp, U. (2007). Modelling nitrogen and phosphorus limitation on phytoplankton growth in Narva Bay, south-eastern Gulf of Finland. Oceanologia, 49(2), 259-276.

Llebot, C., Spitz, Y.H., Solé, J., \& Estrada, M. (2010). The role of inorganic nutrients and dissolved organic phosphorus in the phytoplankton dynamics of a Mediterranean bay: a 
modeling study. Journal of Marine Systems, 83(3-4), 192209. https://doi.org/10.1016/j.jmarsys.2010.06.009

Martin, J.L., Ambrose, R.B., \& Wool, T.A. (2017). WASP8 Macro Algae - Model Theory and User's Guide Supplement to Water Analysis Simulation Program (WASP) User Documentation. Washington DC, U.S.A., U.S. Environmental Protection Agency Office of Research and Development, $37 \mathrm{pp}$.

Moloney, C.L., \& Field, J.G. (1989). General allometric equations for rates of nutrient uptake, ingestion, and respiration in plankton organisms. Limnology and Oceanography, 34(7), 1290-1299.

https://doi.org/10.4319/lo.1989.34.7.1290

Monod, J. (1942). Recherches sur la croissance des cultures bacteriennes, Actualités Scientifiques et Industrielles. Annual Reviews of Microbiology, 3, 3-71.

Oguz, T., Ducklow, H.W., Purcell, J.E., \& Malanotte-Rizzoli, P. (2001). Modeling the response of top-down control exerted by gelatinous carnivores on the Black Sea pelagic food web. Journal of Geophysical Research: Oceans, 106(C3), 4543-4564. https://doi.org/10.1029/1999JC000078

Paasche, E. (1973). Silicon and the ecology of marine plankton diatoms. II. Silicate-uptake kinetics in five diatom species. Marine Biology, 19(3), 262-269. https://doi.org/10.1007/BF02097147

Rhee, G.Y. (1973). A continuous culture study of phosphate uptake, growth rate and polyphosphate in Scenedesmus sp. Journal of Phycology, 9(4), 495-506. https://doi.org/10.1111/j.1529-8817.1973.tb04126.x

Siokou-Frangou, I., Christaki, U., Mazzocchi, M. G., Montresor, M., Ribera d'Alcalà, M., Vaqué, D., \& Zingone, A. (2010). Plankton in the open Mediterranean Sea: a review. Biogeosciences, 7, 1543-1586. https://doi:10.5194/bg7-1543-2010

Sommer, U. (1991). A comparison of the Droop and the Monod models of nutrient limited growth applied to natural populations of phytoplankton. Functional Ecology, 5, 535-544. https://doi.org/10.2307/2389636

Sunda, W.G., Shertzer, K.W., \& Hardison, D.R. (2009). Ammonium uptake and growth models in marine diatoms: Monod and Droop revisited. Marine Ecology Progress Series, 386, 29-41.

https://doi.org/10.3354/meps08077

Vichi, M., Lovato, T., Lazzari, P., Cossarini, G., Gutierrez Mlot, E., Mattia, G., ... Zavatarelli, M. (2015). The Biogeochemical Flux Model (BFM): Equation Description and User Manual BFM version 5.1 (BFM Report series No. 1). Bologna, Italy, The BFM System Team, $87 \mathrm{pp}$.

Yücel, N. (2013). Monthly Changes in Primary and Bacterial Productivity in the North-Eastern Mediterranean Shelf Waters (PhD Thesis). Middle East Technical University, Mersin, Turkey.

Yılmaz, D. (2006). Temporal variation of phytoplankton in the northeastern shelf of the Mediterranean Sea: Composition, pigment signature and production (PhD Thesis). Middle East Technical University, Mersin, Turkey. 